\title{
El color como parte de la estrategia de persuasión política: El caso de los XVI Juegos Panamericanos, Guadalajara 2011
}

\author{
Andrés Valdez Zepeda, Delia A. Huerta Franco y Sergio Díaz González \\ (Universidad de Guadalajara - México)
}

Recibido: 4/11/2011

Aprobado: 13/12/2011

\begin{abstract}
Resumen: En este trabajo los autores analizan el uso del color en las estrategias de persuasión política que utilizan los partidos y los candidatos durante los procesos electorales. También se describe la utilización que los principales partidos políticos de México hacen de los colores para lograr un posicionamiento y una diferenciación política. Específicamente, se indaga sobre el uso del color en los XVI Juegos Panamericanos celebrados en Guadalajara en octubre del 2011. Por ejemplo, se señala que el azul fue el color preponderante en la decoración de las instalaciones deportivas, los hoteles de la ciudad, los automóviles oficiales y en la publicidad del evento, lo que formaba parte de una estrategia ante las próximas elecciones federales del 2012.
\end{abstract}

Palabras clave: Estrategias / persuasión / partidos / México / XVI Juegos Panamericanos / Guadalajara 2011 / identidad política y social

The colors as part of the strategy of political persuasion: The case of the XVI Pan American Games Guadalajara 2011

Summary: In this paper, we analyze the use of color as part of the political persuasion strategies used by parties and candidates during elections. We also present a description of the colors used by the main political parties in Mexico to achieve political positioning and differentiation. We analyze, specifically, the use of color in the XVI Pan American Games in Guadalajara in October 2011. It is noted that the predominant use of blue in the decorations of the sports facilities, hotels, official cars and the event's advertising, among other things, were part of a strategy for the forthcoming 2012 federal elections.

Keywords: Strategies / persuasion / political parties / Mexico / XVI Pan American Games / Guadalajara 2011 / political and social identity 


\section{Introducción}

$\mathrm{H}$ istóricamente, el color se ha utilizado como parte de las estrategias de persuasión en diversas áreas: social, comercial, religiosa, militar y política. En el área social, por ejemplo, los colores festivos se utilizan para embellecer las calles, las casas, la vestimenta de la gente, hasta los templos y las plazas públicas. En el área comercial, los consumidores suelen asociar ciertos rasgos de personalidad con colores específicos, denotando, por ejemplo, excitación, novedad, sofisticación y belleza, entre otras cosas. En el área religiosa, los colores se han usado para adornar templos, vestir santos e identificar credos. Por ejemplo, el verde se asocia con el islamismo, el rojo con el cristianismo, el blanco con el budismo, el azofrado con el hinduismo, el amarillo con el judaísmo y el azul con el catolicismo. Para esta última religión, el azul es el color del cielo, mientras que el negro es el color del inframundo. En el área militar, los colores verde, marrón y olivo son característicos de los uniformes y vehículos militares.
En el ámbito político, los colores son los distintivos comunes de las banderas y los símbolos patrios, además de usarse como distintivos o emblemas partidistas e ideológicos. ${ }^{1}$ Al respecto, en una enciclopedia electrónica se dice lo siguiente:

Los colores como el azul y el rojo están entre los más empleados por su asociación a la derecha e izquierda política, respectivamente. Incluso, tiene una tradición más antigua que el propio origen del concepto de espectro político (izquierda-derecha) originado en la Revolución Francesa, pues se incluían en una expresión muy extendida para designar las diferencias sociales: la oposición entre sangre azul y sangre roja (Wikipedia, en línea).

En diferente forma e intensidad, el ser humano es influido en su conducta y comportamiento por los colores, ya que estos generan y despiertan respuestas emocionales. De esta forma, el factor psicológico del ser humano se ve influido por el ambiente creado por el color, que puede ser de alegría, tristeza, calma, recogimiento o, incluso, violencia. ${ }^{2}$

1 Al respecto, Alicia Sánchez Ortiz (1999) afirma que el color es un símbolo de poder y orden social: "El uso político de nombres de colores es una constante en la historia mundial y un recurso frecuente en cualquier sistema codificado. Con el transcurrir del tiempo, las connotaciones políticas de los colores, nacidas en la Europa occidental, se han ido internacionalizando de manera que han cubierto progresivamente un territorio cada vez más extenso".

2 El color, como un elemento de estrategia política, ha sido utilizado desde hace más de un siglo; es innegable la asociación histórica que se hace de lo "bueno" a lo blanco y lo "negro a lo malo". 
En la política electoral, el color ha jugado un papel muy importante como parte de las estrategias de persuasión durante las campañas electorales, usado para hacer más atractivos y visibles los signos y símbolos políticos. ${ }^{3}$ De hecho, históricamente la gran mayoría de los partidos han adoptado distintos colores que les ayudan a formar su identidad y tratar de diferenciarse política e ideológicamente. En muchos casos, estos colores están normados y claramente definidos en los estatutos partidistas, y son utilizados como parte de los logotipos y emblemas de los partidos. ${ }^{4}$ Durante las campañas, los colores se han usado como instrumento de persuasión, aplicándose en los diferentes objetos de propaganda electoral sea esta utilitaria, escrita, gráfica, mediática o digital, dotándole de colorido y sentido de identidad y pertenencia.

El color ha sido objeto de estudio a lo largo de más de dos mil años. En pleno siglo XXI, hay quienes aseguran que, a pesar de estos estudios, a la fecha seguimos aprendiendo cosas nuevas sobre cómo nos afecta el color y la importancia que tiene en nuestra vida (Gilbert 2009).
En este artículo se analiza el uso del color como parte de las estrategias de persuasión política, de cara a la elección presidencial del 2012 en México, por parte de los organizadores de los XVI Juegos Panamericanos, celebrados en la ciudad de Guadalajara, durante la segunda quincena del mes de octubre del 2011.

Esta gran fiesta de América se caracterizó no solo por la competencia deportiva y la "hermandad" entre las naciones del continente, sino también por su colorido, en la que se usó preponderantemente el esmalte azul como parte de las estrategias para lograr una afirmación identitaria de los millones de espectadores de esta justa atlética -quienes presenciaron los juegos, ya sea por televisión o en forma directa- con el gobernante Partido Acción Nacional (PAN) en los ámbitos estatal y nacional.

Se parte de la hipótesis de que en la política nada se da por casualidad y todo tiene una intencionalidad, ya que en este caso se usó el color como parte de una estrategia sublime de persuasión ante una elección presidencial.

3 La palabra candidato deriva del término cándido, que significa blanco o impoluto. En la Roma antigua los candidatos a los diferentes puestos de elección popular vestían de blanco porque eran personas sin mancha o con una alta reputación social.

4 Un logotipo (coloquialmente conocido como logo) es un elemento gráfico, verbo-visual o auditivo que identifica a una persona, empresa, institución o producto. Los logotipos suelen incluir símbolos coloridos claramente asociados a quienes representan. 


\section{La importancia del color}

Imaginar un mundo sin color es imaginar un mundo sin vida. Cuentan que fue Aristóteles quien describió los colores básicos, aquellos que se relacionaban con los cuatro elementos: el fuego, la tierra, el aire y el agua.

La utilización de los colores de la naturaleza, comenzó en la prehistoria, cuando el hombre primitivo, al recolectar piedras para su adorno personal, manchó sus manos con la tierra que las recogía. Así fue como el rojo ocre se convirtió en el primer color usado por el hombre en sus dibujos en las cavernas y ceremonias fúnebres. Los colores de la prehistoria fueron tres: el marrón o rojo ocre, el gris y el negro (Educared 2009). Existe evidencia de esos colores en los incipientes dibujos que quedaron en las cavernas prehistóricas.

En Egipto, el color se utilizó para preparar curas y medicamentos. Kathia Gilbert (2009) señala que los pisos egipcios eran de color verde y que el azul era otro color importante, ya que era el esmalte del cielo. Los egipcios fueron pioneros en la construcción de templos-hospitales donde usaban gemas y cristales, antecedente de lo que hoy se conoce como cromoterapia, una terapia alternativa para curar dolores y algunos padecimientos.
“Hay papiros que datan de 1550 años antes de Cristo que hablaban de las 'curas de color'", anota la citada autora.

Han pasado más de trescientos años desde que Isaac Newton comenzó a experimentar con el color, cuando al pasar un rayo de luz por un prisma descubrió siete colores y que al pasar esos colores por otro prisma, el rayo de luz nuevamente se hacía blanco. Ya se sabía que el negro es la ausencia de color y con su experimento Newton reafirmaba la teoría de que el blanco es la conjunción de todos los colores.

\section{Los efectos persuasivos del color}

La psicología del color es el estudio del efecto que tienen los colores sobre el humor, el comportamiento y las emociones humanas. (Schnauzer 2009). ${ }^{5}$

En la mercadotecnia política, el estudio del color y su efecto en las emociones de los ciudadanos es un terreno casi virgen, ya que son muy pocas las referencias bibliográficas que enfatizan en el color como estrategia de una campaña electoral o como elemento de identidad de un partido político con sus simpatizantes.

El color evoca emociones y sensaciones distintas; muchas de ellas dependen del lugar en el mundo donde se encuentren las personas. Según al-

5 Aunque los colores han estado presentes a lo largo de toda la historia del hombre, la psicología del color es un área relativamente nueva, que no ha sido aceptada totalmente por las corrientes principales de la psicología. 
gunos autores, "Una de las propiedades psicológicas de los colores es que son capaces de evocar determinados valores afectivos, emocionales o conceptuales" (León y Ávila Charaund 2001). Entonces, el color es algo subjetivo, ya que el significado y la connotación pueden variar de una persona a otra $^{6}$ y de una cultura a otra. ${ }^{7}$

Un ejemplo casi universal es el color blanco. En las sociedades occidentales, significa "pureza y virtud"; por eso los vestidos de novia de esta parte del planeta son, en su mayoría, blancos. Sin embargo, las novias musulmanas visten de negro. También al otro lado del continente, en Asia, el blanco significa "luto", en la India el color rojo es el color que representa la "pureza". Las diferencias culturales en las connotaciones del color son históricas. Cada nación y cada pueblo desarrollaron, a lo largo del tiempo, sus propios códigos de significación de algunos colores.

En este orden de ideas, es importante tomar en cuenta la percepción psicológica del significado de los colo- res. Enrique Serrano (2009) señala que los colores azul y verde tienen "connotaciones positivas" y que el naranja y rojo, que son colores cálidos, tienen "connotaciones negativas".

El color es una experiencia subjetiva (Wilson 1981) que puede movilizar distintas emociones. Al observar un color, diversas sensaciones comienzan a producirse en distintas áreas de nuestro ser. Wilson cita al filósofo del siglo XIX William James, quien dijo: "Aunque parte de lo que percibimos viene a nuestros sentidos del objeto que tenemos delante, otra parte (y quizá la mayor) procede siempre... de nuestra cabeza".

Los colores están presentes de muchas formas en la vida de las personas, más de las que pudiéramos imaginarnos. Al respecto, la psicóloga alemana Eva Heller (2004) sostiene: “Los colores y sentimientos no se combinan de manera accidental, sus asociaciones no son cuestiones de gusto, sino de experiencias universales profundamente enraizadas desde la infancia en nuestro lenguaje y nuestro pensamiento". ${ }^{8}$

6 La manera como una persona "ve" un color no es fácil de explicar y medir, porque puede variar de una persona a otra y depende del lugar del mundo en el que se encuentre y qué tipo de cultura o experiencia ha tenido.

7 A escala internacional, hay algunos códigos de colores cuyos significados son comunes a todas las culturas y se han estandarizado en ciertos símbolos. Las señales de tránsito son un claro ejemplo de esto: así, el verde significa "siga" en todo el mundo, porque tiene una connotación positiva. Por su parte, "el amarillo es luz 'preventiva' porque significa cautela y el rojo es 'alto' por su connotación negativa” (Serrano 2009).

8 Heller (2004) afirma que cada uno de los colores puede generar distintos efectos, con frecuencia antagónicos. Por ejemplo, el color rojo puede asociarse a lo erótico, a la pasión, a 
Heller (citada en Serrano 2009) aplicó una prueba a una muestra heterogénea de personas, a quienes les pidió que asignaran uno de un total de trece colores a más de doscientos conceptos distintos, como amor, tranquilidad, originalidad, envidia, seguridad, astucia, belleza, fealdad, odio, modernidad y anticuado, entre otros.

En ese experimento, Heller (2004) descubrió que la mayoría de los encuestados asoció el concepto "realeza" con el color púrpura. De esta manera, encontró que el significado cultural de un color no solo tiene orígenes históricos, psicológicos y políticos, sino también económicos, debido a que el púrpura es un color muy difícil y caro de reproducir en la naturaleza. Este color se obtenía de unos caracoles llamados "cañadillas".

Se necesitaban hasta diez mil caracoles para producir un gramo de tintura. Los fenicios fueron los primeros en crear las primeras telas teñidas de púrpura. Más tarde, los romanos utilizaron este color como distintivo de la dignidad imperial.

En los tiempos de Jesús de Nazareth, el color púrpura estaba asociado con la realeza, la dignidad y el respeto; pero cuando los soldados de Poncio Pilatos prepararon a Jesús para su crucifixión, le confeccionaron una corona de espinas y una toga púrpura, digna del "rey de los judíos". Muchos años después, el púrpura se convirtió en el color distintivo de la sotana de los cardenales y del Papa. Explica Serrano (2009) que fue en 1556 cuando el papa Pío V, en el momento de su elección como pontífice, decide usar el hábito blanco, y desde esa fecha ha sido la costumbre adoptada por sus sucesores. Según Heller (2004),

[...] los efectos simbólicos del color ocurren como resultado de una experiencia comunicada, mas no necesariamente personal. La experiencia sensorial pasa por el filtro del análisis y las estructuras teóricas, donde recibe un significado abstracto. El color desarrolla un valor de signo. Durante la experiencia de la comunicación intercultural, la información simbólica pasa de una generación a otra como experiencia cultural. También así se transmiten las creencias y los valores: con o sin el soporte de la experiencia personal.

Los colores también representan un país y es importante conocer el significado de las percepciones psicológicas e históricas de los colores. Generalmente, en muchos casos,

[...] son los colores de su bandera y tienen una simbología muy concreta dentro de las naciones. Los colores de

la brutalidad e, incluso, a la nobleza. Por su parte, el color verde puede significar salud o, "veneno," aunque para otros llega a ser tranquilizador. El amarillo se ha asociado a los celos, al apetito, pero también a la vida. 
la bandera de México, por ejemplo, son los mismos del Ejército Trigarante que consumó la independencia del país: el verde simboliza la esperanza del pueblo en el destino de su raza; el blanco, representa la pureza de los ideales del pueblo; y el rojo, simboliza la sangre que derramaron los héroes por la patria. En cambio, para la cultura estadounidense (cuya bandera de las barras y estrellas son azul, blanca y roja), los colores combinados de verde, blanco y rojo tienen una distinta connotación: son los colores de la Navidad (Serrano 2009).

Entonces, es comprensible que los colores del Partido Revolucionario Institucional (verde, blanco y rojo) tengan, para muchos, connotaciones de "patria" y "nacionalismo" y sean aprovechados por los políticos de este instituto como fuertes elementos de identidad que van más allá de la gesta electoral.

\section{Los efectos políticos del color}

El color ejerce diferentes efectos en el comportamiento político de la ciudadanía. Al menos, se han documentado nueve funciones del color que impactan en el comportamiento de los electores.

En primer lugar, el color logra captar la atención de los votantes, ya sea por la luminosidad que aporta a los diferentes elementos de propaganda, por las sensaciones que genera a la vista de la gente o por las emociones que moviliza. De esta forma, el color genera respuestas automáticas de nuestro sistema nervioso, ayudando a atraer la atención, ya que los elementos cromáticos producen un estado de ánimo en el elector. Es decir, el color cumple una función fática.

En segundo lugar, el color siempre connota algo, ya sea formalidad, feminidad, frescura o violencia, según sea el caso, formando una significación cultural y social a lo largo de los años. En el área política, los colores se han usado para connotar poder, solemnidad, unidad, diferenciación, paz o patriotismo, entre otras cosas.

En tercer lugar, el color siempre referencia algo. Es decir, cumple una función referencial. Desde el punto de vista político, por ejemplo, los colores blanco, verde y rojo son asociados por los mexicanos como los colores patrios, así como lo es el amarillo y verde para el caso de los brasileños.

En cuarto lugar, el color genera una mejor visibilidad social. En este sentido, el color aumenta la eficacia y atención de la propaganda y puede ayudar a que los electores distingan mejor las diferentes ofertas político-electorales.

En quinto lugar, el color aumenta la sensación de sabor y deseabilidad, lo cual es aprovechado por muchas organizaciones empresariales para vender mejor sus productos o servicios; y por organizaciones políticas y sociales para tratar de hacer más atractivos a sus candidatos o liderazgos. 
En sexto lugar, el color es un gran instrumento persuasivo. De hecho, en el área del diseño industrial se considera que la forma y el color de los productos juegan un importante rol en la persuasión de los clientes. El poder persuasivo del color se genera en el hecho de que es procesado en el nivel subconsciente. En este sentido, la propaganda electoral, cuando se apoya en una adecuada combinación de colores, se hace más persuasiva y agradable. Es decir, también los colores tienen sus propiedades: simbolizan significados y producen ciertos efectos psicológicos en la conducta y el comportamiento de los electores.

En séptimo lugar, los colores producen diferentes reacciones emocionales y afectan el estado de ánimo de la gente. ${ }^{9}$ La tristeza o la alegría, la ira o el miedo se pueden movilizar no solo a través del uso de las imágenes y las palabras, sino también por el uso del color. Es decir, los colores también provocan sensaciones y movilizan sentimientos y emociones, incidiendo en el estado de ánimo de las personas. ${ }^{10}$

En octavo lugar, el color crea ambientes armónicos y facilita la sinto- nía de los espacios. En consecuencia, la logística electoral y la propaganda de campaña usan los colores con el fin de generar ambientes más armónicos y atractivos para lograr los propósitos centrales de los partidos y sus candidatos.

Finalmente, el color genera una personalidad específica no solo confiriendo un significado a las cosas, a las organizaciones y a las personas, sino también dotándolas de una personalidad e identidad específicas. Los políticos utilizan los colores en su vestimenta y en su propaganda no solo para diferenciarse, sino también reafirmar su propia identidad y personalidad.

$\mathrm{Al}$ respecto, hay quienes afirman, por ejemplo, que el color verde dejó de ser una tendencia, para convertirse en una ideología y movimiento político: "Para los ecologistas, el verde simboliza la naturaleza, la salud, la democracia, la no violencia y la justicia social. Los partidos verdes, activos hoy en más de 100 países, forman parte de la Red Global Verde" (Oppenheim 2009). ${ }^{11}$

En suma, los colores y la política están íntimamente ligados, ya que el

9 "El cromatismo se refiere al impacto emocional que producen en el individuo los colores que se asignan a ciertos elementos que identifican al partido, como son el logo y el símbolo" (Lerma 2005).

10 A través de los colores el ser humano puede expresar su humor, su temperamento, su imaginación y su sentimiento.

11 El color verde es también el color de algunas organizaciones no gubernamentales. Greenpeace es un claro ejemplo de esto: “La mayoría de las veces, los activistas están uniformados, pero no con el color verde oliva, sino con el anaranjado, el color que produce más simpatía según la psicología del color" (Wahl 1997). 
color es un elemento que aporta identidad al partido y sus candidatos, hace más visible y atractiva su propaganda, moviliza emociones, logra un efecto en la conducta y el comportamiento de los votantes; tiene una connotación sociológica, ideológica e histórica. Lo mismo se usa en la vestimenta de los políticos como en la propaganda de los partidos y sus candidatos.

\section{Colores y campañas electorales}

Las campañas electorales son procesos rutinarios de las democracias modernas que implican acciones intensas de persuasión, comunicación y movilización política de los ciudadanos, que se realizan por parte de organizaciones y personas con el objetivo, por un lado, de ganar la mayoría de los votos para alcanzar una posición de representación política y, por el otro, para evitar que los opositores obtengan la posición de poder.

Históricamente, las campañas electorales se han apoyado en diferentes herramientas publicitarias, las cuales han usado el color como instrumento para lograr la visibilidad, la identidad social y la persuasión, ya que la combinación de estas puede tener un efecto muy importante sobre los electores potenciales (Hernández et al., 2007).

Desde la precampaña, y más precisamente durante la campaña electoral, los diferentes aspirantes a un puesto de elección popular usan distintos logoti- pos, emblemas, fotografías, mensajes y eslóganes que presentan a través de diversos medios a los ciudadanos con el fin de cortejarlos y seducirlos para ganar su voto. En toda la propaganda de campaña, la elección del color y su combinación son primordiales, ya que formarán parte de toda la papelería básica del candidato, como las tarjetas de presentación y hojas membretadas, los folletos, los carteles, las pancartas, las bardas y los objetos utilitarios, entre otros.

Sin duda, el color es uno de los elementos más importantes en el diseño de una campaña y puede ser un aliado estratégico básico de un candidato para llamar la atención y lograr la persuasión de los electores.

Históricamente, los colores se han asociado con el lenguaje y frecuentemente con determinadas ideologías e inclinaciones políticas: "[...] en el siglo XIX y la primera mitad del siglo XX, los colores tuvieron un claro significado político, en particular después de la Guerra Civil Española" (Nieto 2000). Hay dos colores, por ejemplo, que en España aún se asocian a dos vertientes e ideologías políticas antagonistas: el azul y el rojo.

El color azul se asocia a posturas derechistas y el rojo a orientaciones más izquierdistas o comunistas. Ramón Nieto (2000) dice que "[...] tras la Guerra Civil, se instruía a los niños para no pronunciar rojo, recurriendo en su lugar a encarnado. Por su parte, el color blanco se ha asociado a posturas 
cristianas, pero finalmente adoptó un significado más de neutro o de centro".

Lerma (2005) explica el significado de once colores para tomar en cuenta en el diseño de los identificadores del partido y recomienda su uso en los elementos gráficos de una campaña política:

- Blanco.- Es el color neutro por excelencia y el que se ve con más frecuencia. Se utiliza como fondo, porque resalta los colores que están junto a él, en especial los tonos oscuros con los que se hace mayor contraste. Como símbolo, es el color de la pureza, la paz, el infinito, la tranquilidad y el espacio.

- Negro.- Es la ausencia del color, el opuesto al blanco. Es impactante cuando se combina con tonos claros. También es símbolo de la elegancia, cuando es brillante o se combina con dorado o plateado.

- Gris.- Es un color neutro, pasivo, algo frío. Se encuentra en el centro, entre el negro y el blanco. Su número de tonos es infinito. Simboliza la meditación, la indecisión, la duda, la melancolía y, en algunos casos, la ausencia de energía. Combina bien con el mayor número de colores.
- Verde.- El color de la naturaleza y en especial de la vegetación, es el más tranquilo y relajante, no transmite alegría pero tampoco tristeza o pasión. Al igual que Heller (2004), Alejandro Lerma (2005) señala que el verde es el color de la esperanza; con un tono amarillento se hace más vivo y alegre, mientras que si se aproxima más al azul se vuelve más frío. ${ }^{12}$

- Café.- Este color es confortable, discreto, equilibrado y realista. Es el color de la tierra y de los troncos de los árboles. Se trata de un color masculino.

- Rojo.- El color de la sangre, del fuego; es fuerte, enérgico y agresivo. Significa pasión, amor, sensualidad, combate y violencia. Cuando se combina con tonos fríos (blanco, azul negro) les da viveza y fuerza.

- Rosa.- Es el color femenino, romántico, suave y alegre; el color de la timidez, la ternura, la intimidad y el candor. Proyecta tranquilidad y cierta vitalidad. No es frecuente ver que se use en símbolos partidarios.

- Naranja.- Es un color sumamente fuerte, alegre, estimulante y explosivo, más vital que el amarillo y el

12 En la actualidad, el verde es mucho más que un color, sus significados contradictorios lo catapultan como uno de los colores más populares de estos tiempos. Desde hace varias décadas, el verde se ha asociado a movimientos políticos y ecológicos internacionales, con la finalidad de hacer conciencia del cambio climático y las repercusiones que está teniendo el planeta. Además, el verde tiene un valor simbólico en las banderas de muchas de las naciones. 
rojo, por lo que se le utiliza con frecuencia en la propaganda de campaña en combinación con los colores representativos de los partidos.

- Amarillo.- Es el color más luminoso, el del sol, la luz y el oro; es alegre, activo, cálido y expansivo. Hace buen contraste con tonos oscuros, confiriéndoles luz y vida, pero suele perderse junto a los claros como el blanco, a menos que esté circundado por uno más oscuro.

- Azul.- Es elegante, frío y tranquilo; el color de la meditación y del espacio, del cielo y del mar; simboliza la tristeza, la imaginación y la profundidad.

- Violeta.- Resulta de la mezcla del azul y el rojo. Simboliza el arrepentimiento, la reflexión y la meditación; es algo melancólico y místico.

Históricamente, los diferentes partidos políticos han usado los colores y sus diferentes combinaciones no solo como un instrumento de persuasión, sino como un medio que les genera identidad y posicionamiento político.

En general, las campañas electorales ganadoras son aquellas que se distinguen por ser coloridas y brillantes; muchas de ellas logran convertirse en grandes movimientos sociales y populares, constituyéndose en elementos destacados de las democracias modernas. De ahí la importancia de usar el color antes, durante y después de estas "gestas electorales" como parte de las estrategias de persuasión política.
En el diseño gráfico de una campaña es importante incorporar a los expertos en colorimetría, psicología del color y cromatismo, ya que su experiencia y formación ayudará a diseñar la mejor imagen gráfica de la campaña, lo cual puede convertirse en una importante ventaja competitiva. Al respecto, Lerma (2005) recomienda también hacer una prueba de los diseños acerca de los identificadores del partido mediante técnicas como el grupo de enfoque, con el fin de seleccionar los diseños y las combinaciones de colores que resulten más convenientes.

\section{Los colores, los partidos y las campañas electorales en México}

Las campañas electorales en México, históricamente han sido acompañadas por los colores. La primera campaña presidencial se organizó en 1828, en la cual participaron como candidatos Vicente Guerrero, Manuel Gómez Pedraza y Anastasio Bustamante, quienes realizaron proselitismo para obtener el voto de las legislaturas locales que les permita obtener la mayoría de los sufragios necesarios para ganar la Presidencia de la República.

Estas campañas fundacionales se apoyaron en los colores que identificaban a las tres diferentes opciones políticas para tratar de hacerlas más atractivas e interesantes para los electores. Vicente Guerrero, por ejemplo, en su campaña usó los colores del Ejército Trigarante (blanco, verde y rojo). Por 
su parte, Gómez Pedraza utilizó los colores azul y blanco (históricamente asociados a los grupos conservadores del país), mientras que Anastasio Bustamante utilizó los colores distintivos del Rito Yorkino de las logias masónicas. $^{13}$

En los tiempos actuales, los partidos políticos nacionales se han apoyado en los colores no solo para impulsar y publicitar sus campañas electorales, sino también para generar una identidad político-partidista y crear o reforzar la construcción de marca. De hecho, en México, para referirse a los partidos, algunas personas lo hacen nombrándolos por los colores: los "amarillos", los "blanquiazules", los "tricolores", los "naranjas", etcétera.

Tal es el caso, por ejemplo, del Partido Revolucionario Institucional (PRI), que utiliza los colores de la bandera nacional (blanco, rojo y verde) como parte de su identidad partidista usado en su logotipo y en su propaganda política. De acuerdo con el artículo quinto de sus estatutos,

[...] el emblema y los colores que caracterizan y diferencian al Partido se describen como sigue:
Un círculo dividido en tres secciones verticales destacadas en color verde, blanco y rojo, de izquierda a derecha, respectivamente, enmarcadas en fondo gris la primera y la última, y en fondo blanco la segunda. En la sección verde estará impresa en color blanco la letra "P"; en la sección blanca, y en color negro la letra " $R$ "; $y$ en la sección roja, la letra "I" en color blanco. La letra " $\mathrm{R}$ " deberá colocarse en un nivel superior a las otras dos (Partido Revolucionario Institucional, en línea).

Más adelante, en este mismo artículo, se señala que "Los órganos del Partido y sus candidatos en campaña deberán utilizar el emblema, los colores y el lema del partido".

En el caso del Partido Acción Nacional (PAN), este instituto político utiliza los colores azul y blanco en su emblema y en su propaganda electoral. De acuerdo con el artículo séptimo de sus estatutos, "El emblema de Acción Nacional es un rectángulo en color plata, en proporción de 1 x 3,5, que enmarca una franja rectangular colocada horizontalmente en la parte media y dividida en tres campos de colores verde, blanco y rojo, ${ }^{14}$ respectiva-

13 Los partidos políticos (Liberal y Conservador) tomaron la tradición, proveniente de Europa y de los Estados Unidos, de distinguirse por colores, por elementos específicos $\mathrm{y}$, principalmente, por estandartes y escudos que daban a conocer, en cierta forma, los lineamientos del pensamiento masónico de cualquiera de las dos tendencias (Universidad Autónoma del Estado de México, en línea).

14 A pesar de que se contempla en los estatutos el uso de los colores patrios, el PAN no los ha utilizado como distintivo institucional ni en las campañas electorales. 
mente, y en letras mayúsculas de color azul, las palabras ACCION en el extremo superior izquierdo y NACIONAL en el extremo inferior derecho".

En este mismo artículo se señala que "El distintivo electoral de Acción Nacional es un círculo de color azul vivo, circunscribiendo las letras mayúsculas PAN del mismo color azul sobre fondo blanco, enmarcado en un cuadro de esquinas redondeadas, también de color azul" (Partido Acción Nacional, en línea).

Para el caso del Partido de la Revolución Democrática (PRD), su emblema distintivo es el sol azteca y los colores partidistas son el amarillo y el negro. ${ }^{15}$ Estos colores se usan como distintivo partidista y como parte de la propaganda durante las campañas electorales. El Partido Convergencia (PC), hoy Movimiento Ciudadano (MC) utiliza el color naranja como parte de su emblema y en sus campañas electorales. Finalmente, el Partido Verde Ecologista de México (PVEM) utiliza el verde, el blanco y el negro.

En México, el uso de los colores como parte de la identidad partidista no se limita a las campañas electorales $\mathrm{y}$ actos partidistas, sino que trasciende y comúnmente se usa como los colores distintivos de los gobiernos emanados de los diferentes partidos políticos. De esta manera, por ejemplo, es común que los gobiernos panistas usen el color azul en la papelería oficial, en los logotipos y emblemas de gobierno o pinten de azul los señalamientos vehiculares y la infraestructura de la ciudad. A su vez, los gobernantes priístas suelen vestir camisas rojas en los actos públicos. En su publicidad gubernamental, el rojo es un color muy usado y también se utiliza, por ejemplo, en el diseño de las placas de los vehículos automotores.

Por su parte, los perredistas, además de vestir con camisas o corbatas amarillas en los actos públicos, han impulsado sendas campañas institucionales para tratar de fortalecer la unidad e identidad partidista. Ejemplo de esto han sido las campañas "El amarillo nos une" o "Hagámoslo amarillo". Finalmente, el Movimiento Ciudadano ha impulsado campañas publicitarias tratando de posicionar el naranja como el color ligado a la esperanza y el cambio político en México.

\section{El color en los Juegos Panamericanos}

Los XVI Juegos Panamericanos se celebraron del 15 al 30 de octubre del 2011 en la ciudad de Guadalajara, México. En este singular evento participaron más de seis mil deportistas provenientes de 42 naciones del continente americano.

15 Los colores del partido son el amarillo en el fondo y el negro en el sol y las letras. 
El color fue un elemento distintivo en esta gesta deportiva, en la que el azul predominó como esmalte y lustre que cubrió los principales escenarios e instalaciones deportivas. De hecho, este color estuvo presente no solo en la infraestructura, los señalamientos y las invitaciones al festejo, sino incluso en las premiaciones y los magnos eventos de inauguración y clausura.

A continuación se enumeran los casos de la utilización del color azul más evidentes:

1. El logotipo de los juegos panamericanos "Guadalajara 2011" fue coloreado de azul o pintado de blanco sobre un manto azul, utilizando una tipografía modernista, muy similar a la que han utilizado en los últimos años los panistas en las campañas electorales.

2. Los estadios e instalaciones deportivas también fueron coloreadas preponderantemente de azul, así como la propaganda en mantas, lonas espectaculares o pancartas gigantes, anuncios plásticos y banderolas.
3. Las edecanes y los voluntarios que apoyaron en la organización de los juegos portaban uniformes oficiales, que incluía playeras o vestidos en color azul.

4. Los estrados, las tarimas o las plataformas donde se premiaba a los deportistas ganadores de medallas también fueron pintados de azul.

5. Una de las tres mascotas de los juegos, ${ }^{16}$ llamada Gavo, también fue de color azul, era la planta de agave, originaria de Tequila.

6. En las premiaciones importantes, vistas por millones de ciudadanos a través de la televisión, como fue el caso de la entrega de la medalla de oro al equipo mexicano de fútbol, a ellos se les otorgó la mascota de color azul, mientras que a los que ganaron la medalla de plata y de bronce se les hizo entrega de las mascotas amarilla y roja, respectivamente. Esto mismo sucedió en la ceremonia de clausura, al entregar la medalla de oro y la mascota azul al brasileño Solonei Silva en el maratón varonil de 42 kilóme-

16 Las tres mascotas de los juegos fueron: Gavo, un agave azul originario de Tequila, Jalisco, al que le gusta pasear en bicicleta, principalmente en la montaña, también el atletismo, el canotaje, el fútbol, y sobre todo cuidar el medio ambiente. Leo, un león que representa el escudo de Guadalajara, es voluntario de los Juegos Panamericanos, además de coleccionista de medallas de oro, le encanta ayudar a las personas con capacidades especiales; y Huichi, una venadita originaria de Tapalpa; ella practica la danza folclórica, la gimnasia artística, el taekwondo y el deporte ecuestre; además, le gusta mucho la lectura y disfruta la jericalla (postre típico mexicano que tiene origen en la ciudad de Guadalajara; se prepara con leche, huevos, vainilla, canela y azúcar). 
tros, mientras que a los colombianos Diego Alberto Colorado y Juan Carlos Cardona, ganadores de las medallas de plata y de bronce, se les entregó las mascotas roja y amarilla, respectivamente.

7. Por último, los diferentes comentaristas del canal de televisión estatal de Jalisco (C7), perteneciente al Sistema Jalisciense de Radio y Televisión, al festejar la entrega de las medallas de oro para los deportistas mexicanos comentaron jubilosos, en varias ocasiones, que esa "medalla de oro sabía a PAN".

Además, los hoteles, los camiones, los taxis, los automóviles oficiales y los aparadores publicitarios de la zona metropolitana de Guadalajara, así como las páginas de Internet, se pintaron todos de azul, tratando de lograr fijar entre los espectadores de esta justa deportiva una identidad política que asocie los "buenos resultados", la festividad y el éxito con el color azul, el color distintivo del logotipo del PAN.

\section{El color y la identidad partidista}

Por identidad se entiende el reconocimiento y la conciencia de nuestra propia memoria, de nuestro propio yo, de nuestros gustos, de nuestras simpatías y antipatías, filias y fobias en un tiem- po y espacio determinados. ${ }^{17}$ De acuerdo con Islas (2011), la identidad es la conciencia que permite reconocernos dentro de un grupo específico, debido a las similitudes de pensamiento, ideologías, metas e intereses.

En opinión de Fitts (1966), la identidad es uno de los principales factores que describen la percepción que una persona tiene de sí mismo (autopercepción). Para R. S. Erikson (Erikson et al. 1976), es la capacidad que posee una persona para integrar su autopercepción e imagen (quién es) que tiene del mundo con sus actos. Supone tener conocimiento claro y preciso de sus capacidades, intereses, actitudes, objetivos, normas, gustos y valores.

Por su parte, Laing (1966) señala que la identidad es un ritual de confirmación, el cual reafirman y unifica el concepto que cada persona tiene de sí mismo. La identidad es una fuente de fortaleza de tipo ideológico que proporciona un sistema de ideas que brindan una imagen del mundo convincente. La identidad incluye un sentido de futuro y de comportamiento anticipado.

Para Frank (1977), la identidad es el motor que impulsa al hombre a actuar, a sentir, y que le dota de un concepto unificado del mundo y de él mismo. Es saber quiénes somos y estar a gusto con ello; conocer qué queremos y lu-

17 Del latín identitas. La identidad es el conjunto de rasgos propios de un individuo o de una comunidad. 
char por obtenerlo dentro de las reglas que nos dictan nuestras propias normas y valores..$^{18}$ Es decir, la identidad funciona como un elemento cohesionador que fundamenta el sentimiento de pertenencia. Es un proceso fundamental para la construcción del sujeto y la sociedad.

Tajfel y Turner (1986) señalan que como parte del proceso de identidad, la persona debe reunir tres características: primera, percibir que pertenece al grupo; segunda, ser consciente de que por pertenecer a ese grupo se le asigna un calificativo positivo o negativo; y tercera, sentir cierto afecto derivado de la conciencia de pertenecer a un grupo.

En el área política, la identidad es una orientación afectiva y valorativa hacia un determinado partido, color, organización, grupo, candidato, ideología o plataforma programática que implica pertenencia a algo o coincidencia con alguien. ${ }^{19}$ La identidad política es la conciencia que permite al individuo reconocerse dentro de un grupo social determinado, debido a las similitudes de pensamiento, ideologías, intereses, historia, visión de futuro y metas que se plantean. ${ }^{20}$

Las identidades políticas son identidades colectivas orientadas a la participación directa en el ejercicio del poder o a la intervención sobre los poderes públicos en términos de influencia y de presión (Giménez, en línea). Son atajos cognitivos y afectivos que simplifican la toma de decisiones y proporcionan una guía para interpretar la información y evaluar opciones y propuestas políticas.

La identidad política también puede ser definida como una orientación individual de tipo afectivo y valorativa hacia un partido político y sus colores emblemáticos, ${ }^{21}$ una ideología, una personalidad o líder, un programa, un grupo, una organización, un movimiento o una causa. Al identificarse el individuo con otro o con alguien o algo, comparte y refleja su afinidad, su

18 Con la identidad, el hombre logra alcanzar un significado que satisface su propia voluntad de sentido, ayudándole además a superar la frustración y su vacío existencial (Frank 1977).

19 Por su parte, la identidad de un político con cierto partido lo define en la medida en que lo obliga a mantener una relación de respeto y colaboración con el ideario y la plataforma programática de la asociación partidista a la que pertenece.

20 Hay que diferenciar entre identidad política e identidad nacional. Esta última se refiere a aquella identidad de una persona que se relaciona con la nación a la cual pertenece, sea por haber nacido en tal territorio, por formar parte de una comunidad o por sentir lazos de pertenencia con las costumbres y tradiciones de tal nación (Definicionabc, en línea).

21 La identidad partidista fue un concepto acuñado para dar cuenta de la estabilidad de las preferencias políticas en una democracia (Campbell et al. 1960). 
aprecio, su comunión, su similitud y su cercanía.

Este tipo de identidad implica, de cierta forma, un sentimiento de comunidad, solidaridad, pertenencia, afiliación, sentido y lealtad (Braud 1980), ya sea con la organización, con sus dirigentes o con su ideología, con el programa o con sus símbolos, colores y emblemas. Además, la identidad política también implica la exposición doctrinal, ideológica y programática, así como la difusión de símbolos y rituales participativos.

Por su parte, la identidad social puede ser definida como el vínculo afectivo y valorativo generado a raíz de compartir algo en común con otro, como puede ser un mismo origen, una misma raza, una misma religión, un mismo idioma, un mismo género o un mismo lugar de nacimiento o de procedencia, entre otros.

La identidad social es un proceso de autoinclusión, el cual implica que los individuos se autoperciben como parte de algo, por el simple hecho de tener algo en común con otro. El pensar en nosotros como miembros de un grupo se le define como una identidad social (Tajfel y Turner 1979). Es un proceso de reconocimiento de su participación dentro de las relaciones sociales. Es decir, establece el qué y el dónde se encuentra la persona en términos sociales.

La identidad es fuente de significado y experiencia para las personas. Castells (1997) define la identidad como el proceso de construcción de significado basado en atributos culturales.

A su vez, la identificación es el proceso psíquico por el cual una persona se siente vinculada afectiva y valorativamente con otra o con algo, aceptando y compartiendo sus características o cualidades. Implica tener plena conciencia de pertenecer y ser integrante de algo y de actuar para alcanzar los fines comunes que se persiguen.

Para la escuela sociológica, la pertenencia de los individuos a las clases o grupos sociales influye tanto en la creación de los partidos políticos como en la identificación con estos. Esta perspectiva sostiene que las divisiones sociales son la fuente de las orientaciones ideológicas y, finalmente, de la identidad política (Converse y Dupeux 1962; Fleury y Lewis-Beck 1993; McDonough, Barnes y López Piña 1988; Sani 1976). Por su parte, para la escuela psicológica, la afiliación partidista es una predisposición afectiva del individuo, adquirida mediante la socialización con diferentes grupos, liderazgos y organizaciones que tiende a reforzarse con el tiempo (Campbell et al. 1960).

A diferencia de los enfoques anteriores, la perspectiva racionalista (Downs 1957, Fiorina 1981, Shively 1979) concede una importancia crucial a la experiencia política de los individuos, así como a las evaluaciones prospectivas y retrospectivas del gobierno de turno, ya que estas pueden 
cambiar la afinidad partidista de un individuo en el curso de una elección (Estrada 2005).

El color genera una identidad social y política en la que ciertos individuos se identifican tanto con un partido político como con sus colores distintivos. En el caso que nos ocupa, el color azul fue preponderantemente usado en los Juegos Panamericanos de Guadalajara 2011, como parte de las estrategias de los actuales gobernantes panistas con el fin de formar una identidad política y social con los espectadores de estos juegos, orientado a obtener una ventaja competitiva para enfrentar las elecciones de este año.

El éxito en la organización de los Juegos Panamericanos y el resultado de la delegación de deportistas mexicanos, que obtuvo 133 medallas, de las cuales 42 fueron de oro, aunado a su alta cobertura mediática y a una evaluación crítica favorable de estos por parte de la mayoría de los comunicadores, también generó un efecto positivo en materia de formación de simpatías e identidades políticas y sociales benéficas para el partido gobernante: el PAN.

\section{El poder electoral de la identidad}

La identidad, en la que se incluye la identidad partidista a partir del color distintivo del instituto político y su apropiación por parte del electorado, genera cierto tipo de empoderamiento de los individuos dentro de un grupo. Las personas con una identidad social se perciben más similares con los de su grupo y tienden a actuar bajo patrones conductuales análogos (Brown 1988); tienden a ser más cooperativos con los integrantes y dirigentes del grupo (Brown 1991); sienten la necesidad de estar de acuerdo con las opiniones del grupo, generando un efecto del tipo la espiral del silencio ${ }^{22}$ (Goofman 1971); perciben los mensajes de grupo como de mejor calidad que los otros grupos y se relacionan en comportamiento y actitud (Tajfel y Turne 1986).

De cierta manera, la identidad colectiva genera en los individuos tanto poder referencial como real, ya que la propia existencia perceptiva de grupo los cohesiona, los hace muchos más participativos, tienden a seguir el comportamiento grupal y, sobre todo, se enfocan en conseguir metas y obje-

22 La espiral del silencio es una teoría de las ciencias políticas y la comunicación propuesta por la politóloga alemana Elisabeth Noelle-Neumann en su libro La espiral del silencio. Opinión pública: nuestra piel social (1995), donde estudia la opinión pública como una forma de control social en la que los individuos adaptan su comportamiento a las actitudes predominantes sobre lo que es aceptable y lo que no. La teoría de la espiral del silencio parte del supuesto básico de que la mayor parte de las personas tienen miedo al aislamiento, y al manifestar sus opiniones primero tratan de identificar las ideas, para luego sumarse a la opinión mayoritaria o consensuada (Noëlle-Neumann 1995). 
tivos establecidos, ya sea por el grupo o por sus líderes.

En los procesos electorales, la identidad juega un papel de agregación y suma de voluntades, y condiciona un comportamiento político a favor o en contra de algo. De hecho, la identidad social y política, simbolizada, por ejemplo, por los colores, se convierte en un gran motivador de la movilización electoral y del voto a favor de una determinada opción o en su contra.

\section{A manera de conclusión}

El color está presente en innumerables maneras en la vida de los seres humanos, ya que evoca emociones y sensaciones, así como despierta sentimientos. En la política, el color y su correcta combinación o contraste otorga identidad a los partidos, genera una mayor visibilidad social, diferencia las propuestas electorales, representa distintas corrientes ideológicas y juega un papel determinante en la persuasión de los electores.

En el caso de los partidos políticos de México, el color ha estado presente desde su fundación. De esta forma, históricamente el PRI ha usado los colores distintivos de la bandera nacional (verde, blanco y rojo). Por su parte, el PAN le ha apostado al azul y al blanco, colores más conservado- res y ligados a símbolos y signos de carácter religioso. ${ }^{23} \mathrm{El}$ PRD le apuesta al amarillo y al negro, mientras que el PVEM y Convergencia (Movimiento Ciudadano) se apoyan en el verde y el naranja, respectivamente.

Los colores, usados en la vestimenta de los políticos, en el emblema o en la propaganda partidista pueden determinar, en cierto grado, la aceptación o el rechazo por parte de los ciudadanos. Las campañas exitosas son aquellas que logran concitar la atención y la movilización política de los electores. En esta movilización, la comunicación y la imagen juegan un papel muy importante. El color está presente tanto en la comunicación gráfica como en la imagen corporativa de las campañas.

El diseño gráfico y la arquitectura visual de una campaña también son elementos importantes para su éxito. En este sentido, bien se puede decir que generalmente las campañas coloridas y brillantes son campañas ganadoras. Por su parte, comúnmente las campañas incoloras y deslucidas son campañas perdedoras.

Es decir, el color es uno de los factores importantes que se deben considerar en el fracaso o el éxito de una campaña electoral, el conocimiento del efecto o impacto del color en las emociones de los ciudadanos y en la generación de simpatías y antipatías

23 Por ejemplo, el manto del vestido que usa la virgen de Guadalupe es azul, como el color del cielo. 
políticas, puede ayudar a los políticos y a sus estrategas a entender y afinar su tino en el diseño de una campaña electoral exitosa.

De igual forma, la identidad en general y la identidad política a partir de un color partidista juegan un papel fundamental en la arena electoral bajo un sistema competitivo de impronta democrática. La identidad que un ciudadano construya respecto de los partidos políticos, sus colores y sus candidatos determinará, en gran medida, la orientación de su voto y la posibilidad de ganar la elección. ${ }^{24}$

De ahí que la formación deliberada de identidades políticas y sociales se está convirtiendo en una estrategia electoral sumamente rentable para las organizaciones políticas y sus candidatos a un puesto de elección popular, ante un escenario de alta competitividad política.

En el caso de los XVI Juegos Panamericanos de Guadalajara 2011, los or- ganizadores utilizaron el color azul de manera preponderante en toda la publicidad, vestimenta, infraestructura y logística con el objetivo de generar una identidad política y social entre millones de espectadores mexicanos a favor de su partido político.

De cierta forma, su efecto persuasivo ya se ha manifestado en la contienda para gobernador en el estado circunvecino de Michoacán, donde la popularidad, aceptación y posicionamiento de la candidata del PAN y Nueva Alianza, Luisa María Calderón ${ }^{25}$ pasó de 29 por ciento a 39 entre los meses de septiembre a noviembre. ${ }^{26}$ Por su parte, Fausto Vallejo, candidato del PRI y del Partido Verde Ecologista de México, bajó de 37 a 33 por ciento, y Silvano Aureoles, candidato del Partido de la Revolución Democrática, Partido del Trabajo y Movimiento Ciudadano, también retrocedió en este mismo periodo, de 34 a 28 por ciento. ${ }^{27}$

24 La identidad partidista es un heurístico simple que, por un lado, con información mínima, le permite al elector inferir muchos aspectos de la oferta de partidos y candidatos y, por otro, generalmente en las campañas, los candidatos tratan de simplificar el dilema que enfrenta el elector en dimensiones muy simples como la continuidad o el cambio de un proyecto, el riesgo y la incertidumbre o la certeza de la experiencia, etcétera.

25 Luisa María Calderón es hermana del presidente de México Felipe Calderón Hinojosa.

26 La encuesta la realizó el Grupo Reforma, las fechas del levantamiento de la última medición correspondiente al mes de noviembre fueron del 26 al 30 de octubre del 2011, justo cuando se realizaban los Juegos Panamericanos.

27 Las elecciones para gobernador, presidentes municipales y diputados locales se realizaron el 13 de noviembre del 2011 en el estado de Michoacán. Los resultados de la elección para gobernador del estado fueron los siguientes: PRI-PVEM 35,39\%; PAN-PNA 32,67\%; PRDPT-PC 28,88\%; nulos 3\%; no registrados 0,05\% (Fuente: Instituto Electoral de Michoacán). 
Sin embargo, la elección presidencial está a nueve meses de distancia, ${ }^{28}$ tiempo aún lejano en la que se puede diluir el efecto persuasivo de los Juegos Panamericanos y olvidar el éxito ${ }^{29}$ tanto en su organización como en el número de medallas obtenidas por los deportistas mexicanos. ${ }^{30}$

\section{Bibliografía}

Braud, W. G. (1980). "Lability and inertia in conformance behavior". Journal of the American Society for Psychical Research 74, 297-318.

Brown, R. J. (1991). Relaciones intergrupales. Barcelona: Ariel.

-. (1988). Social identity and the environment: A commentary. Vol. 45. Dordrech: Kluwer Academic Publishers.

Campbell, J. et al. (1960). The American voter. Nueva York: John Wiley \& Sons, Inc.

Castells, Manuel (1997). The power of identity. Vol. II. Massachusetts: Blackwell Publishers.
Converse, P. y G. Dupeux (1962). "Politicization of the electorate in France and the United States". Public Opinion Q 26.

Definicionabc. "Definición de identidad nacional". Diccionario en línea. $<$ http://www.definicionabc.com/social/identidad-nacional.php $>$.

Downs, An. (1973). Teoría económica de la democracia. Madrid: Aguilar.

EducAred (2009). Wikillerato. <http:// portales.educared.net/wikiEducared/index.php?title=Colores_de_ la_prehistoria>. [Consulta: $18 \mathrm{de}$ mayo del 2010].

Erikson, R. S.; MacKuen, M. B. y J. A. Stimson (2002). The macro polity. Nueva York: Cambridge University Press.

Estrada, L. (2005). "Party identification in Mexico". Tesis doctoral inédita. San Diego: Universidad de California.

Fiorina, M. P. (1981). Retrospective voting in national American elections. New Haven, Conn.: Yale University Press.

28 El presente trabajo se redactó entre octubre y noviembre del 2011 y las elecciones presidenciales se realizarán el 1 de julio del 2012.

29 De acuerdo con Mario Vázquez Raña, presidente de la Organización Deportiva Panamericana, estos juegos fueron los mejor organizados de toda su historia.

30 La delegación de deportistas mexicanos obtuvo el cuarto lugar en los XVI Juegos Panamericanos, detrás de Estados Unidos, Cuba y Brasil, logrando en total 133 medallas (45 de oro, 41 de plata y 50 de bronce). En los XV Juegos Panamericanos, celebrados en el 2007 en Brasil, México obtuvo el quinto lugar, con 73 medallas (18 de oro, 24 de plata y 31 de bronce). 
Fitss, P. M. (1966). “Cognitive aspects of information processing: III. Set for speed versus accuracy". Journal of Experimental Psychology 71(6), 849-857.

Fleury, C. J. y M. S. Lewis-Beck (1993). "Anchoring the French voter: Ideology versus party". The Journal of Politics, vol. 55, 1100-1109.

Frank, V. D. (1977). "Psychiatry, the health invalid". American Journal of Psychiatrv 134, 1340-1355.

Gilbert, K. (2009). "Los orígenes del color". Arte y Comunicación Gráfica VI (61), 40-41.

Giménez, Gilberto. “Cultura política e identidad". <http://www.paginasprodigy.com/peimber/culteident. pdf $>$. [Consulta: 15 de febrero del 2011].

Goofman, E. (1971). Ritual de interacción. Buenos Aires: Tiempo Contemporáneo.

Heller, E. (2004). La psicología del color. Cómo actúan los colores sobre los sentimientos y la razón. $<$ http://dialnet.unirioja.es/servlet/ libro?codigo=254510>. [Consulta: 18 de mayo del 2010].

Hernández, C.: Hernández Sampieri, R. y E. Ocampo Jaramillo (2007). Marketing político e imagen de gobierno en funciones. 3. ${ }^{a}$ edición. México, D.F.: McGraw-Hill Interamericana.

Islas, A. M. (2011). "México: crisis de identidad partidista". <http://www. suite101.net/content/mexico-crisis- de-identidad-partidista-a36583>. [Consulta: 12 de marzo del 2011].

Laing, Ronald et Al. (1966). Percepción interpersonal. Buenos Aires: Amorrortu editores.

León, L. R., y R. Ávila Charaund (2001). Factores ergonómicos en el diseño. Guadalajara (México): Universidad de Guadalajara.

Lerma, A. (2005). Mercadotecnia política y organización de campaña. México, D.F.: Gasca Sicco, S.A. de C.V.

McDonough, P.; Barnes, S. H. y L. A. Pina (1988). "The growth of democratic legitimacy in Spain". American Political Science Review 80, 735-760.

Nieto, R. (2000). Lenguaje y política. Universidad de Sevilla. <http:// www.aloj.us.es/vmanzano/docencia/movsoc/resumen/nieto.pdf.> [Consulta: 16 de mayo del 2010].

Noelle-Neumann, E. (1995). La espiral del silencio. Opinión pública: Nuestra piel social. Barcelona: Paidós.

Oppenheim, C. H. (2009). "El verde es vida". Arte y Comunicación Gráfica VI (61), 19.

Partido Acción Nacional. Estatutos. $<$ http://www.pan.org.mx/portal/reglamentos>. [Consulta: 10 de mayo del 2010].

PARTido Revolucionario Institucional. Estatutos. <http://www.pri.org.mx/ priistastrabajando/pri/documentosbasicos/estatutos.aspx>. [Consulta: 14 de mayo del 2010]. 
SÁnchez Ortiz, A. (1999). "El color, símbolo de poder y orden social. Apuntes para una historia de las apariencias en Europa: espacio, tiempo y forma". Historia Moderna $12,321-864$.

SANI, G. (1976). "Mass constraints on political realignments: perceptions of anti system parties in Italy". British Journal of Political Science 6 (1), 1-32.

Schnauzer, M. (2009). “El color y las emociones". Arte y Comunicación Gráfica VI (61), 48-49.

Serrano, E. (2009). “El color de la cultura". Arte y Comunicación Gráfica VI (61), 42-44.

Shively, P. (1979). “The development of party identification among Adults: Exploration of a functional Model". American Political Science Review 73 (4), 1039-1054.
Tajfel, H. y J. C. Turner (1986). “The social identity theory of intergroup behavior", en Worchel, S. y L. W. Austin (eds.). Psychology of intergroup relations. Chigago: NelsonHall.

. (1979). "An integrative theory of intergroup conflict", en Austin, W. G. S. Worchel (eds.). The social psychology of intergroup relations. Monterey, CA: Brooks-Cole.

Universidad Autónoma del Estado de México, Coordinación de IDENTIDAD UnIVERSITARIA. XXXVI Boletín Informativo del Colegio de Cronistas. Tercera época. http://www.uaemex. mx/identidad/IdnBol51.html\#5. [Consulta: 10 de mayo del 2010].

Wahl, P. (junio de 1997). Cicodi.org. http://www.cicodi.org/Publicaciones/ 